\title{
Synthesis and Characterization of Coated Iron Oxide Nanoparticles Produced for Drug Delivery in Viscoelastic Solution
}

\author{
IULIAN ANTONIAC ${ }^{1,2}$, ALEXANDRU CERNEA ${ }^{1 *}$, CRISTIAN PETCU ${ }^{3}$, DAN LAPTOIU ${ }^{4}$, \\ DIANA TABARAS ${ }^{1}$, CAMELIA TECU ${ }^{1}$, AURORA ANTONIAC ${ }^{1}$, SEBASTIAN GRADINARU ${ }^{5}$ \\ ${ }^{1}$ Politehnica University of Bucharest, Faculty of Materials Science and Engineering, 313 Splaiul Independentei Str., 060042, Bucharest, \\ Romania \\ ${ }^{2}$ Academy of Romanian Scientist, 54 Splaiul Independentei Str., 050094, Bucharest, Romania \\ ${ }^{3}$ ICECHIM - National Institute for Research and Development for Chemistry and Petrochemistry, 202 Splaiul Independentei Str., \\ 060021, Bucharest, Romania \\ ${ }^{4}$ Colentina Clinical Hospital Bucharest, 19-21 Stefan cel Mare BLVD., 72202, Bucharest, Romania \\ ${ }^{5}$ University of Medicine and Pharmacy "Carol Davila" Bucharest, 37 Dionisie Lupu Str, Bucharest 030167, Romania
}

\begin{abstract}
Drug delivery systems enable transportation of drugs in the body, controlling the time, rate or place of the release rendering them ideal for local treatments. When treating joint diseases such as osteoarthritis of the knee the therapeutically substances are given intra-particularly. Magnetic nanoparticles are used so that the solution containing the treatment can be easily directed from the outside with the help of magnets allowing the drug to reach the maximum concentration at the area of interest. Functionalization of nanoparticles is necessary to obtain viscoelastic solutions with optimal physico-chemical and medical properties. This paper presents a superior method of delivering intraarticular hyaluronic acid using iron oxide magnetic nanoparticles $\left(\mathrm{Fe}_{2} \mathrm{O}_{3}\right)$ which were embedded in tetramethylammonium hydroxide (TMOH) and coated using a layer-by-layer technique with hyaluronic acid and inulin. TMOH was chosen for a better dispersion of nanoparticles in the viscoelastic solution, eliminating the risk of agglomerations, hyaluronic acid and inulin being used for medical purposes.
\end{abstract}

Keywords: magnetic nanoparticles, hyaluronic acid, functionalization, viscoelastic solution

\section{Introduction}

Knee disorders are an important cause of pain that can lead to immobilization when they are not treated properly or in a timely manner. Osteoarthritis is the most widespread knee disease in the world and is manifested by destruction of the cartilage of the joint. Pharmacological treatments consist of orally administered steroidal anti-inflammatory drugs, calcium and vitamins, and intra-articular steroid injections. In the final stage, the only treatment option for knee osteoarthritis is surgery consisting of total replacement of the knee joint by knee prosthesis, known as total knee arthroplasty (TKA). In order to minimize the disadvantages such as procedure failure and trauma induced by the invasiveness of the intervention, alternative treatments have been envisaged [1,2]. The treatment with oral and intra-articular drugs have some drawbacks related to low concentrations of the drug reaching the area of interests and reduced mean residence times (to just a few hours) secondary to lymphatic clearance [3]. This inspired researchers to develop drug delivery systems which help and sustain the local drug action, releasing the active substance at the affected site and maintaining it there for a longer period, without a clinically relevant drug leak in the body [4]. Various medical specialties like neurosurgery [5], orthopedics [6-8], general surgery [9-11] or dentistry [12, 13] benefit from new drug delivery systems or advanced biomaterials.

\footnotetext{
*emil: alexcernea07@gmail.com
} 
Drug delivery systems were developed to improve the interactions of active compounds in target areas by controlling the distribution of the drug. Furthermore, these systems have the ability to prevent other side effects of the treatment, improve bioactivity and extend the plasmatic lifetime of the drug [14]. Recently, magnetic particles were used in drug delivery systems from the outside, with the help of external magnets ensuring superior local bioavailability [15-17]. Magnetic nanoparticles (MNPs) possess outstanding physico-chemical and biological properties pertinent to various medical applications. They are especially used in tissue regeneration due to their small size which allows them to interact with cells at nanometric level promoting migration, proliferation, adhesion and growth [1822].

Hyaluronic acid (HA) is being used for a vastitude of medical purposes from contrast agent in radiology to targeted therapy for joint diseases in osteoarthritis [23].

Iron oxide particles are the preferred magnetic nanoparticles due to super magnetism and anisotropy showing also a hydrophobic surface, high saturation field, high field irreversibility and more importantly a high charge allowing them to remain stable in the body under physiological conditions [24]. The size of the nanoparticles is determinant on their magnetic properties and cell encapsulation

Studies show that the optimum particle size should be less than $100 \mathrm{~nm}$. The surface of the MNPs is obviously a very important factor in their use, because it influences their biocompatibility and cell proliferation in the relevant sites [12, 13, 17, 25].

Thus, due to the beneficial effects in treating knee disorders by direct action in the affected area, magnetic nanoparticles began to be used in the viscosupplementation treatment for osteoarthritis pain $[26,27]$. Viscosupplementation treatment is a care therapy consisting of repetitive intra-articular injections with hyaluronic acid (HA), this being used to obtain beneficial hydrogels for tissue regeneration, due to its high biocompatibility [4, 20, 25].

HA is a natural biodegradable polymer, which exists in the human organism as an important component of extracellular matrix (ECM) and plays multiple structural roles such as in communication transduction or growth of macrophages and epithelial tissue cells. It also has anti-adhesive and antimicrobial properties, especially on common orthopedic pathogens.

HA is synthesized by fibroblasts or type B synoviocytes and it is secreted into the joints. In the synovial fluid of a healthy knee joint, HA is found in concentrations from 2.5 to $4 \mathrm{mg} / \mathrm{mL}$ and its essential elastic and viscous properties help maintain the mechanical properties of the knee joint to resist shear forces, stress and shocks.

In a knee affected by osteoarthritis, concentrations of HA are significantly decreased, so the interaction between HA molecules is also diminished. This impairs the functionality of the joint and may lead leading to pain [23]. By using HA in a drug delivery system is possible to maintain the viscosupplements properties avoiding drug crystallization and toxicity, problems commonly encountered with intra-articular injections.

Furthermore, viscosupplementation with HA can stimulate the synoviocytes and synovial fibroblast to secrete natural hyaluronic acid. It will behave as a lubricant, an elastic substance buffering the effects of different forces that strain the joint [22, 25-27].

The novelty of the work is related to the use of coated iron oxide nanoparticles for drug delivery in viscoelastic solutions. Taking into account the beneficial effects of hyaluronic acid on the human body and the direct action of magnetic nanoparticles, viscosupplementation treatment in drug delivery system is a new technique for reducing and treating pain caused by knee diseases such as osteoarthritis.

\section{Materials and methods}

Magnetic iron oxide nanoparticles have been synthesized and functionalized so that nanoparticles with optimal properties in the treatment of knee injuries are introduced into viscoelastic solution 
matrix. Functionalization of the nanoparticles consisted of coating of the magnetic nanoparticles with TMOH, HA and inulin (Figure 1).

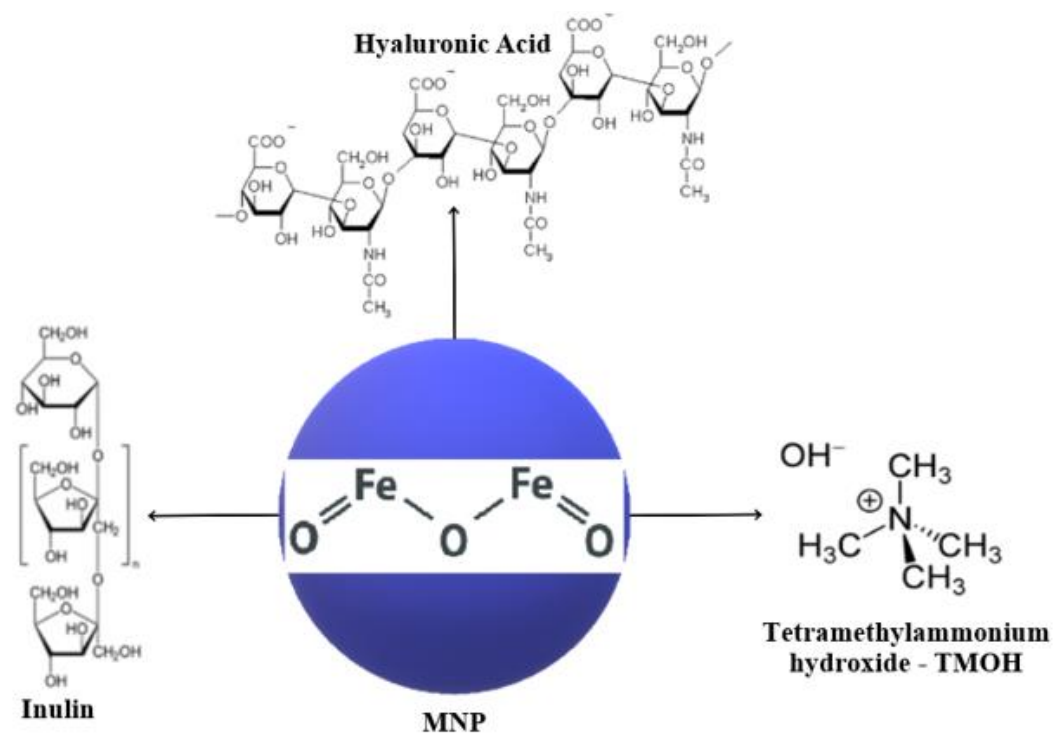

Figure 1. Schematic structure of a functionalized MNP

MNPs were obtained and functionalized in the Nanomaterial Laboratory of ICECHIM, using the co-precipitation method. A representation for the steps employed in the process of synthesis and functionalization of MNPs of $\mathrm{Fe}_{2} \mathrm{O}_{3}$ is shown in figure 2. The dispersion of magnetic iron oxide nanoparticles was achieved by co-precipitating $\mathrm{FeCl}_{2}$ and $\mathrm{FeCl}_{3}$ at the addition of a concentrated solution $\left(25 \% \mathrm{NH}_{4} \mathrm{OH}\right)$ in a mixture of iron salts with a $\mathrm{FeCl}_{2}: \mathrm{FeCl}_{3}$ molar ratio of 1:2. $\mathrm{FeCl}_{2} \cdot 4 \mathrm{H}_{2} \mathrm{O}$ was dissolved in $2 \mathrm{M}$ molar $\mathrm{HCl}$ and $\mathrm{FeCl}_{3} \cdot 6 \mathrm{H}_{2} \mathrm{O}$ in water. It was mixed in a three-necked flask, stirred mechanically under the nitrogen pillow and after homogenization the required amount of $25 \% \mathrm{NH}_{4} \mathrm{OH}$ was added drop wise. The entire mixture was maintained at $65^{\circ} \mathrm{C}$ for one hour, obtaining a black precipitate (Figure 2). The precipitate was washed 3 times with water, the magnetic nanoparticles being drawn to the bottom of the flask with a magnet, and then kept at room temperature for peptization and functionalization. For the next steps, the hyaluronic acid was used in two concentrations: a normal concentration of $32 \mathrm{mg} / 2 \mathrm{~mL}$ and a bigger concentration of $40 \mathrm{mg} / 2 \mathrm{~mL}$, to show the influence of the amount of hyaluronic acid on magnetic nanoparticles in the viscoelastic solution.

Synthesis

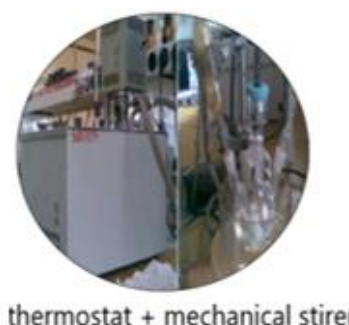

thermostat + mechanical stirer

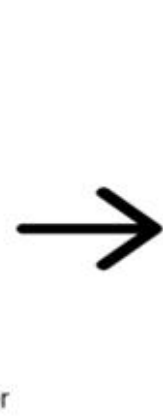

Functionalization

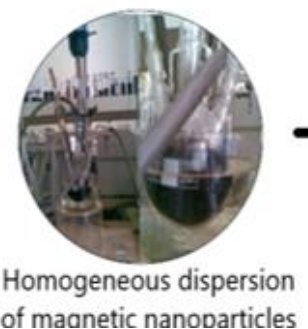

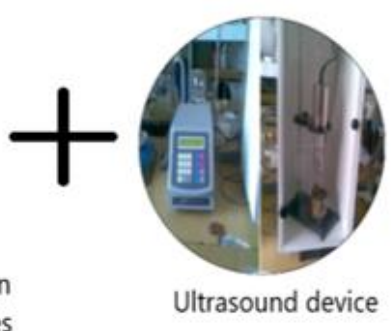

Figure 2. Schematic representation for the followed steps in the process of synthesis and functionalization of magnetic nanoparticles of $\mathrm{Fe}_{2} \mathrm{O}_{3}$

Tetramethylammonium hydroxide - TMOH (Fluka) was used for peptization and hyaluronic acid (Sigma Aldrich) and inulin (Dahlia tubers, Fluka) + hyaluronic acid (Sigma Aldrich) were used for functionalization. Subsequently, MNPs were coated with a layer of TMOH, using a layer-by-layer 
technique. After washing the MNPs, a solution of TMOH (1M) was added, stirred until homogenized and then left overnight for the phenomenon of peptization to take place. Inulin was used for the coating of MNPs with a second layer, using also the layer-by-layer method, by mechanical mixing and by ultrasound (Figure 2). Deposition of hyaluronic acid (HA) on nanoparticles was performed similarly, using two solutions of different concentrations of hyaluronic acid, in order to study the effect of hyaluronic acid concentration on the final properties of biopolymer - magnetic nanoparticles composites. Details about the notation of all experimental samples that were obtained and investigated are shown in table 1.

Table 1. Notation of the samples

\begin{tabular}{cc}
\hline Sample & Composition \\
\hline 1 & MNPs + HA \\
\hline 2 & $($ MNPs + TMOH $)$ \\
\hline 3 & $(($ MNPs + TMOH $)+$ HA \\
\hline 4 & $(($ MNPs + TMOH $)+$ Inulin $)+$ HA \\
\hline 5 & $((M N P s+$ TMOH $)+$ Inulin $)+$ concentrated HA \\
\hline 6
\end{tabular}

For the analysis and characterization of the synthesized and bio-functionalized magnetic nanoparticles the following techniques were used:

- Transmission electron microscopy (TEM) was performed on a high resolution transmission electron microscope type TECNAI F30, in order to obtain crystallographic and structural information on magnetic nanoparticles. The main advantage of this method is the possibility of obtaining simultaneously the diffraction - the structural information - and the images from the same sample area.

- Scanning Electron Microscopy (SEM) was used for the quantification of structural information and for the observation and analysis of the microstructure (morphology) of magnetic nanoparticles, the analysis performed on the scanning electron microscope, type Quanta 200.

- using the Fourier Transform Infrared Spectroscopy method (FT-IR) performed on a JASCO 6200 FT-IR Spectrometer, equipped with a Golden Gate - type attenuated total reflection (ATR) device, information regarding the chemical composition of the samples was obtained; more precisely, identification of the type of characteristic chemical bonds and the modifications that took place during their functionalization.

- Dynamic Light Scattering (DLS) coupled with Laser Doppler Velocimetry (LDV), using a Nano Zetasizer device were used to determine the size and zeta potential (electrokinetic potential in colloidal dispersions) of magnetic nanoparticles dispersed in the viscoelastic solution.

\section{Results and discussions}

The following figures show the results of investigations performed using Scanning Electron Microscopy - SEM, Transmission Electron Microscopy - TEM and Fourier-Transform Infrared Spectroscopy - FT-IR (Figures 3- 7).

The TEM and SEM images show that in the matrix of viscoelastic solution, initially there are associations of magnetic nanoparticles with an asymmetrical contour and variable dimensions (Figure 3). As a result of the coatings the particle shape acquires a more uniform distribution. Figure 4 shows the MNPs coated with a TMOH layer and it turns out that the nanoparticles are stable. The same can be observed after HA coverage (Figure 5). The difference is that after adding HA the particle contour 
is better defined. The final MNPs were successfully incorporated into the two layers (TMOH + HA) (Figure 6), respectively three layers ( $\mathrm{TMOH}+$ Inulin $+\mathrm{HA}$ ) (Figure 7), and resulted in uniform distribution of nanoparticles in the viscoelastic solution.
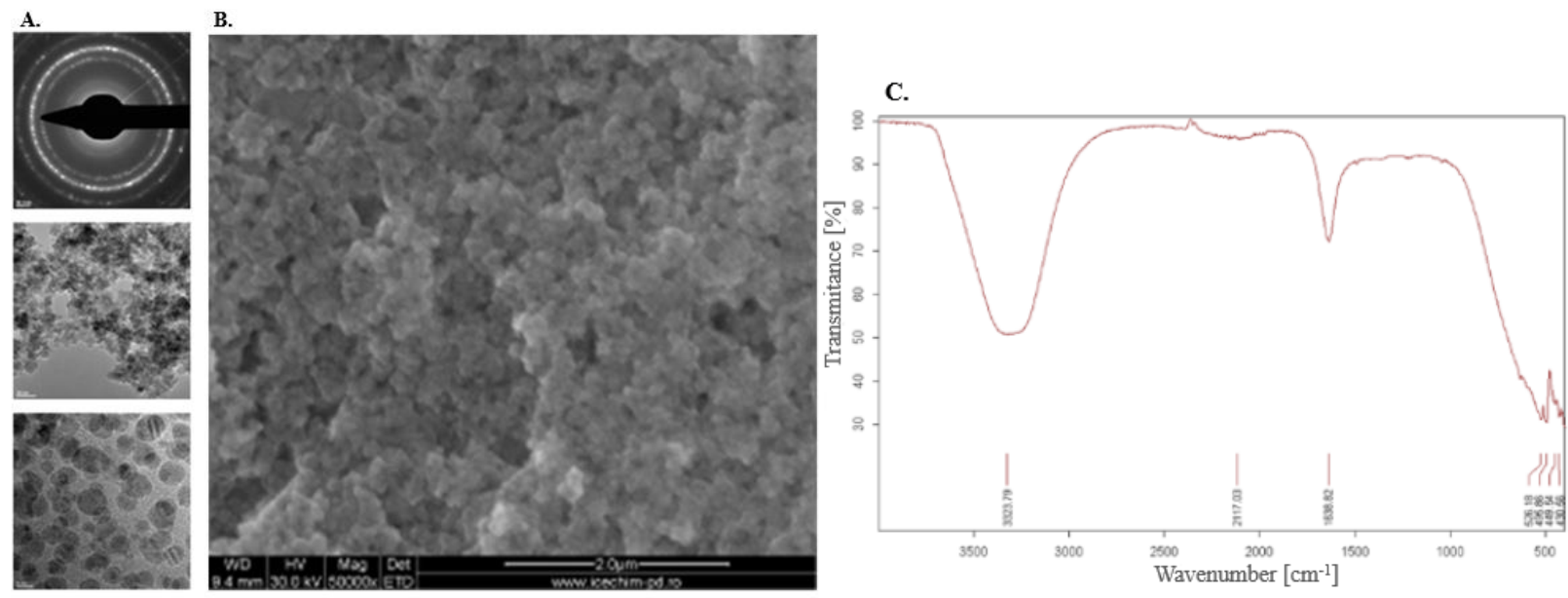

Figure 3. TEM (A), SEM (B) and FT-IR (C) results for the sample 1 (MNPs + HA)

After investigating the experimental samples of MNPs by FT-IR, the spectra generally contain the characteristic band of magnetite $\left(\mathrm{Fe}_{3} \mathrm{O}_{4}\right)$, at the wavelength of $581 \mathrm{~cm}^{-1}$. All the peaks recorded into the interval 400-4000 $\mathrm{cm}^{-1}$ represent bands characteristic of ferroferic nanoparticles. The band at wavelength $630 \mathrm{~cm}^{-1}$, is present in the spectra of all synthesized samples and demonstrates the presence of maghemite $\left(\gamma-\mathrm{Fe}_{2} \mathrm{O}_{3}\right)$. Hematite $\left(\alpha-\mathrm{Fe}_{2} \mathrm{O}_{3}\right)$, represented by the $537 \mathrm{~cm}^{-1}$ band, is also present in the ferrofluidsanalyzed.

For samples covered with HA in different concentrations (Figure 3C) the wide band, from the wavelength of $3340 \mathrm{~cm}^{-1}$, specifies the hydroxyl group $(-\mathrm{OH})$, indicates coating with hyaluronic acid.
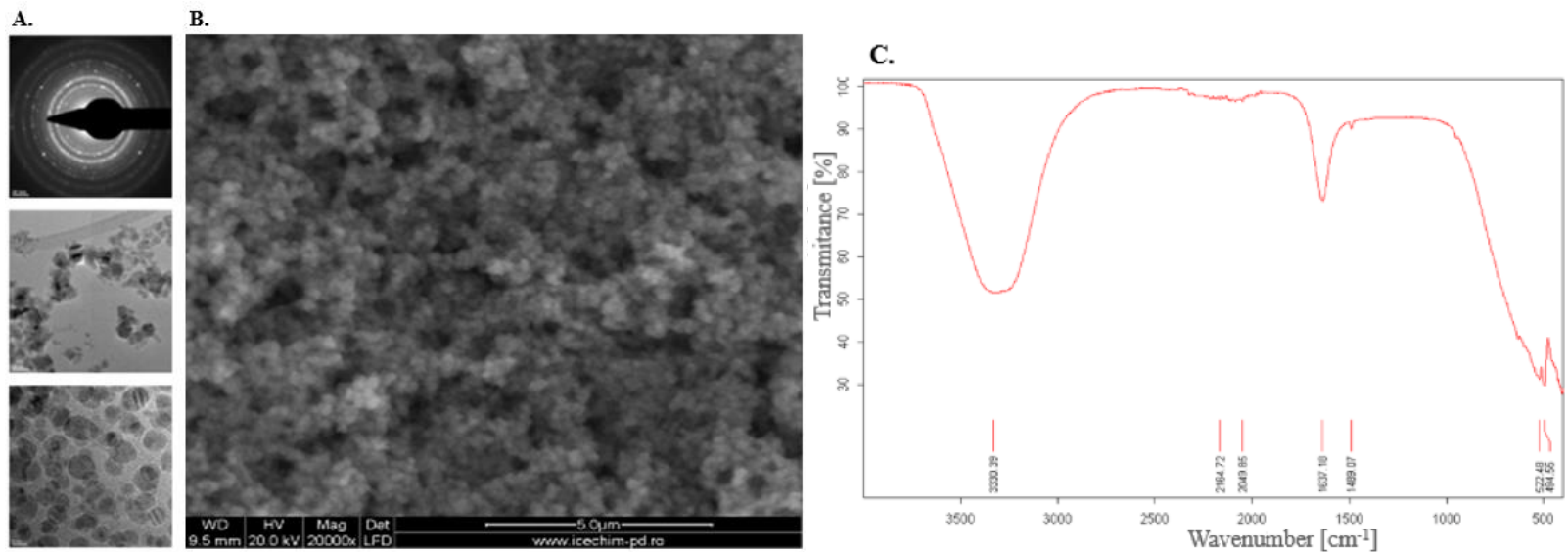

Figure 4. TEM (A), SEM (B) and FT-IR (C) results for the sample 2 (MNPs+ TMOH)

FTIR analysis of MNPs coated with TMOH shown in Figure 4C, present symmetrical and asymmetric stretching vibration of the $\mathrm{OH}$ group which generates a wide band at $3330 \mathrm{~cm}^{-1}$. The intense band from $1637 \mathrm{~cm}^{-1}$ can be determined by both the symmetrical stretching vibration of $-\mathrm{OH}$ from the $-\mathrm{COOH}$ group, as well as by the deformation vibration characteristic of the $\mathrm{C}-\mathrm{N}$ group from the TMOH. The representative band from $1489 \mathrm{~cm}^{-1}$ is due to the vibration caused by the asymmetric stretch from $-\mathrm{C}=\mathrm{O}$ from the $-\mathrm{COOH}$ group. 

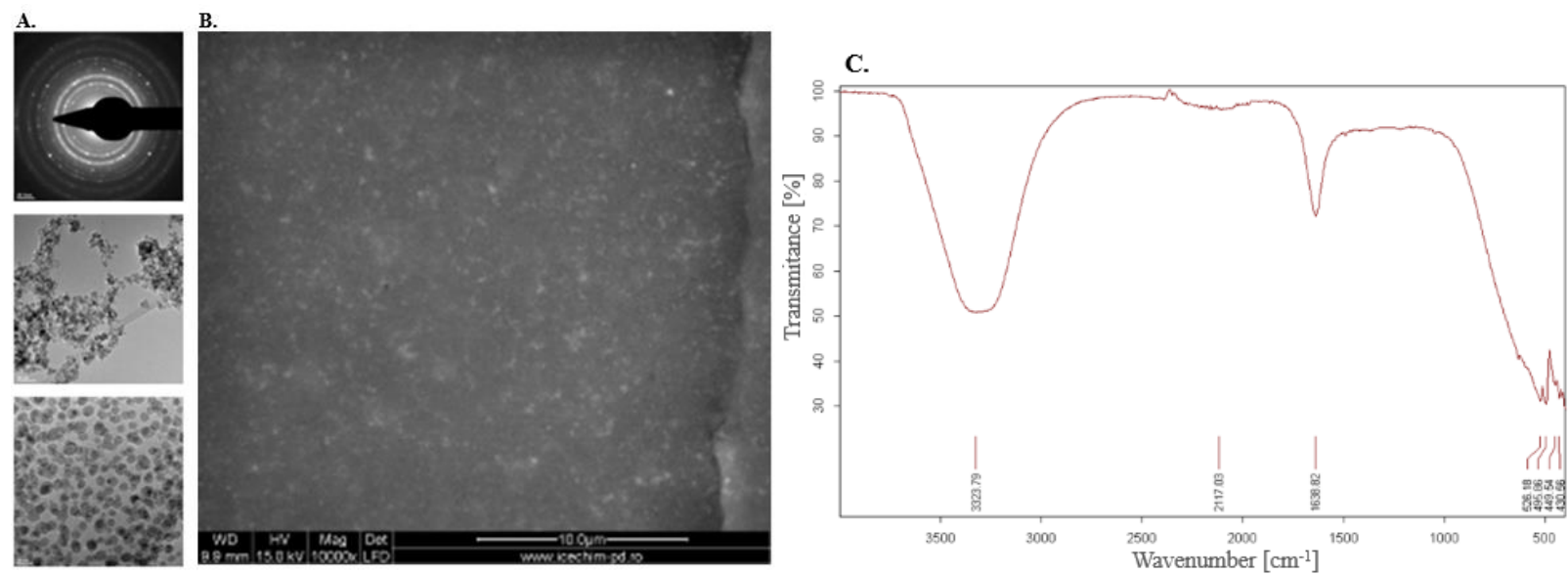

Figure 5. TEM (A), SEM (B) and FT-IR (C) results for the sample 3 (MNPs + TMOH) + HA

In the samples covered with TMOH and HA (Figure 5C) it is noted that the wide band, from 3340 $\mathrm{cm}^{-1}$, specify the hydroxyl group $(-\mathrm{OH})$, indicating the coated with HA.

MNPs coated with the inulin layer (Figure $6 \mathrm{C}$ ), but also MNPs coated with inulin and HA (Figure 7C), exhibit a wide band, at the wavelength of $3450 \mathrm{~cm}^{-1}$, due to symmetrical and asymmetrical stretching vibration specific to the group - $\mathrm{OH}$. We note an intense peak at $1636 \mathrm{~cm}^{-1}$ given by the symmetrical stretching vibration from $-\mathrm{OH}$ in the $-\mathrm{COOH}$ group, groups present in both inulin and hyaluronic acid.
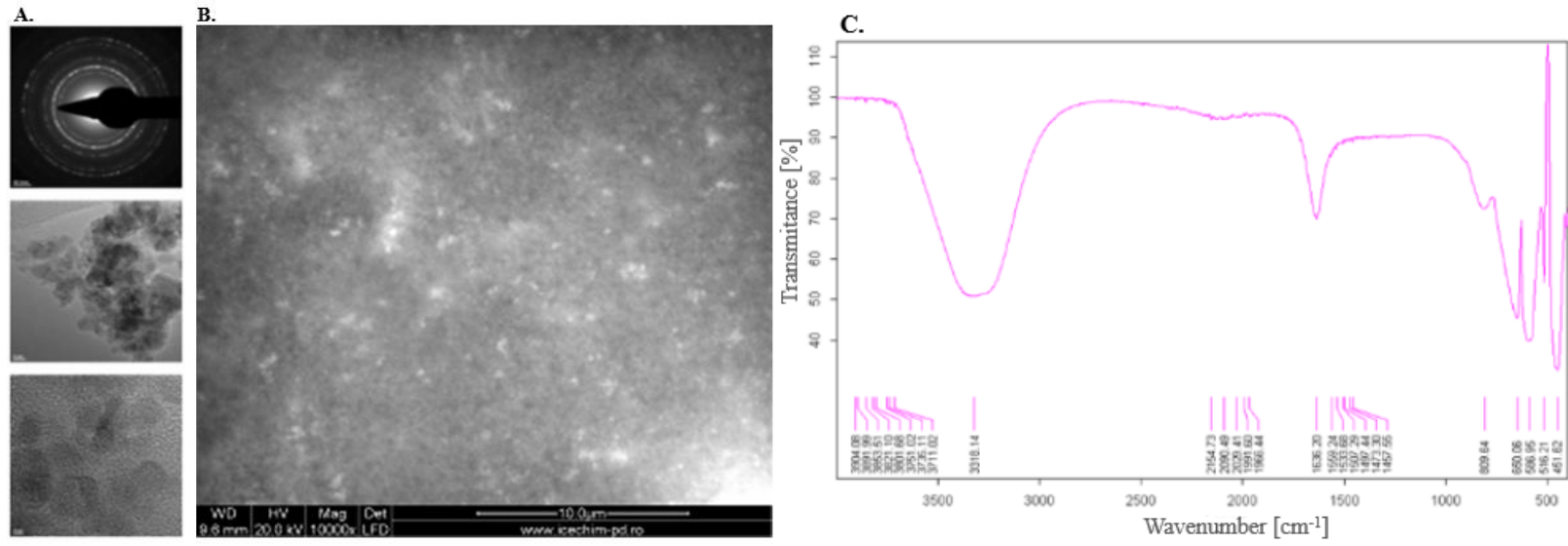

Figure 6. TEM (A), SEM (B) and FT-IR (C) results for the sample $4(\mathrm{MNPs}+\mathrm{TMOH})+$ Inulin
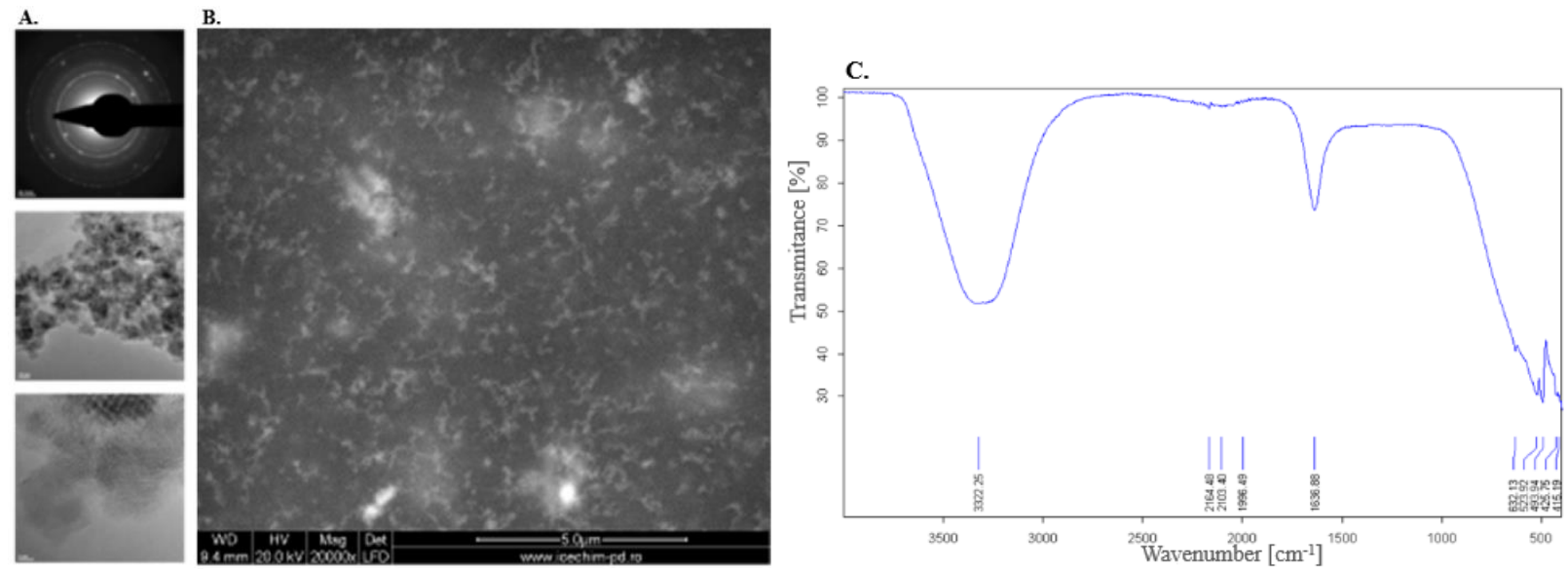

Figure 7. TEM (A), SEM (B) and FT-IR (C) results for the sample $5((\mathrm{MNPs}+\mathrm{TMOH})+$ Inulin $))+\mathrm{HA}$ 
The results of the DLS analysis - Dynamic Light Scattering (shown in Figure 8) regarding the size of nanoparticles embedded in a viscoelastic solution, are summarized in Table 2. The zeta potential of MNPs in the viscoelastic solution was determined by the LDV - Laser Doppler Velocimetry technique (Figure 9).

Table 2. The experimental values of the nanoparticles sizes and zeta potential of the experimental samples

\begin{tabular}{|c|c|c|c|}
\hline Nr. & Composition of the Samples & $\begin{array}{l}\text { DLS } \\
(\mathbf{n m})\end{array}$ & $\begin{array}{l}\text { Zeta Potential } \\
\text { (mV) }\end{array}$ \\
\hline 1 & MNPs + HA & 118 & -62.7 \\
\hline 2 & $(\mathrm{MNPs}+\mathrm{TMOH})$ & 43.6 & -42.4 \\
\hline 3 & $((\mathrm{MNPs}+\mathrm{TMOH})+\mathrm{HA}$ & 50.1 & -29.7 \\
\hline 4 & $((\mathrm{MNPs}+\mathrm{TMOH})+$ Inulin $)$ & 101.6 & -51.5 \\
\hline 5 & $((\mathrm{MNPs}+\mathrm{TMOH})+$ Inulin $)+\mathrm{HA}$ & 76.9 & -42.4 \\
\hline 6 & $((\mathrm{MNPs}+\mathrm{TMOH})+$ Inulin $)+$ concentrated HA & 243.4 & -40.6 \\
\hline
\end{tabular}

The initial MNPs are in the form of agglomerates with dimensions around $109.4 \mathrm{~nm}$ (figure 8 a) and Zeta potential having a value of $-44.6 \mathrm{mV}$ (figure $9 \mathrm{a}$ ).

The agglomerates deposit very quickly on the bottom of the container, which is why it is necessary to stabilize the magnetic nanoparticles by coating them with a TMOH layer (peptization). After coating with TMOH (Figure $8 \mathrm{~b}$ ), stable MNPs were formed, which do not deposit in time and the resultant particle sizes were $43.6 \mathrm{~nm}$.
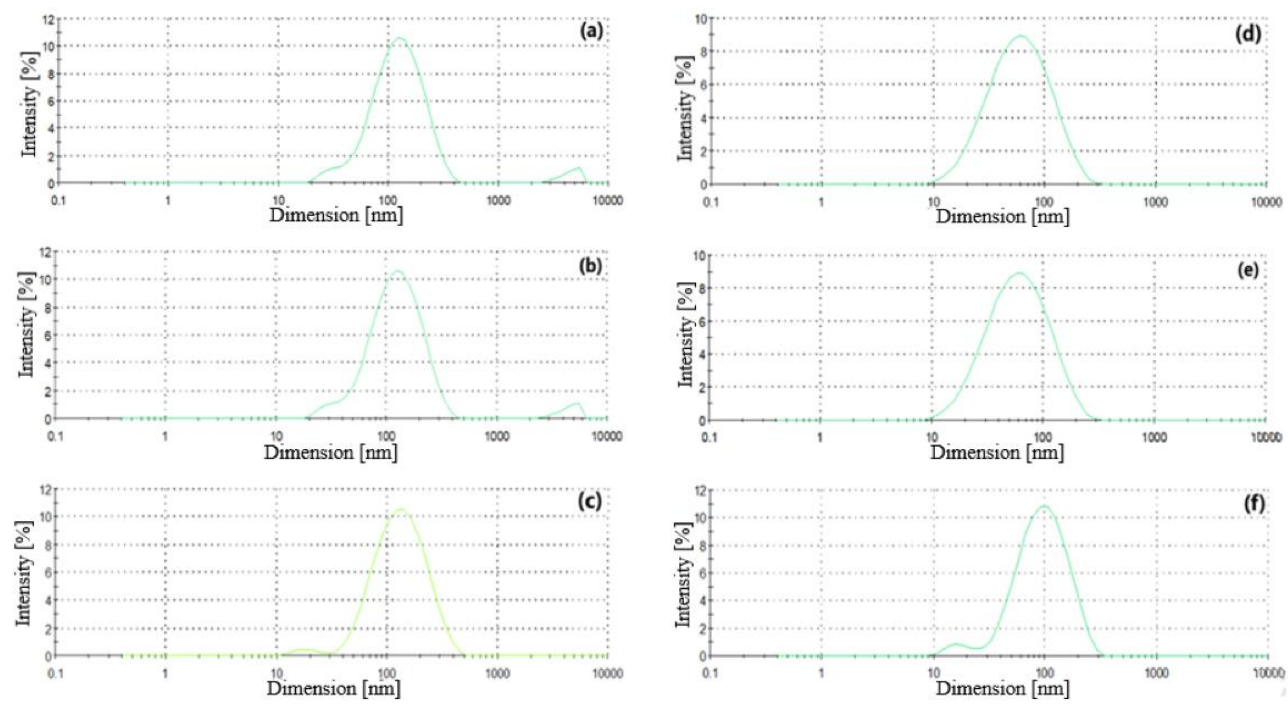

Figure 8. Particle size distribution result after DLS analysis: a) the initial MNPs;

b) MNPs + TMOH; c) $(\mathrm{MNPs}+\mathrm{TMOH})+$ concentrated HA; d $(\mathrm{MNPs}+\mathrm{TMOH})+$ Inulin;

e) $((\mathrm{MNPs}+\mathrm{TMOH})+$ Inulin $)+\mathrm{HA} ; \mathrm{f})((\mathrm{MNPs}+\mathrm{TMOH})+$ Inulin $)+$ concentrated HA

The addition of the inulin layer does not have a significant influence on the size of the nanoparticles because it increases the particle size up to $50.14 \mathrm{~nm}$, and agglomerations of the 
nanoparticles do not form. These results are according to the previous research made by Marinescu [4] and Antoniac [25].

When hyaluronic acid was added in two different concentrations, in a ratio of 1:10, MNPs with dimensions of $76.9 \mathrm{~nm}$ (Figure $8 \mathrm{e}$ ) and $243.4 \mathrm{~nm}$ (Figure $8 \mathrm{f}$ ) were obtained for the 10-fold higher concentration. The Zeta potential does not change visibly, having a value of about $-40.6 \mathrm{mV}$ (Figure 9 f). It was observed that the samples with lower HA concentrations are more stable in time than those with high concentrations, the smaller particle size being an important factor in ensuring stability.

In MNPs coated with one layer (NPM $+\mathrm{TMOH})$, the addition of concentrated HA produced a biopolymer composite type of biomaterial with nanoparticles of relatively similar dimensions with those of MNPs coated with two layers(NPM + TMOH) + Inulin). This observation corroborated with the Zeta potential values suggest that even with the use of two coating layers the dispersion in HA is equally effective. The observation is in agreement with the previous similar results obtained by Ivirico [1] and Cojocaru [17].
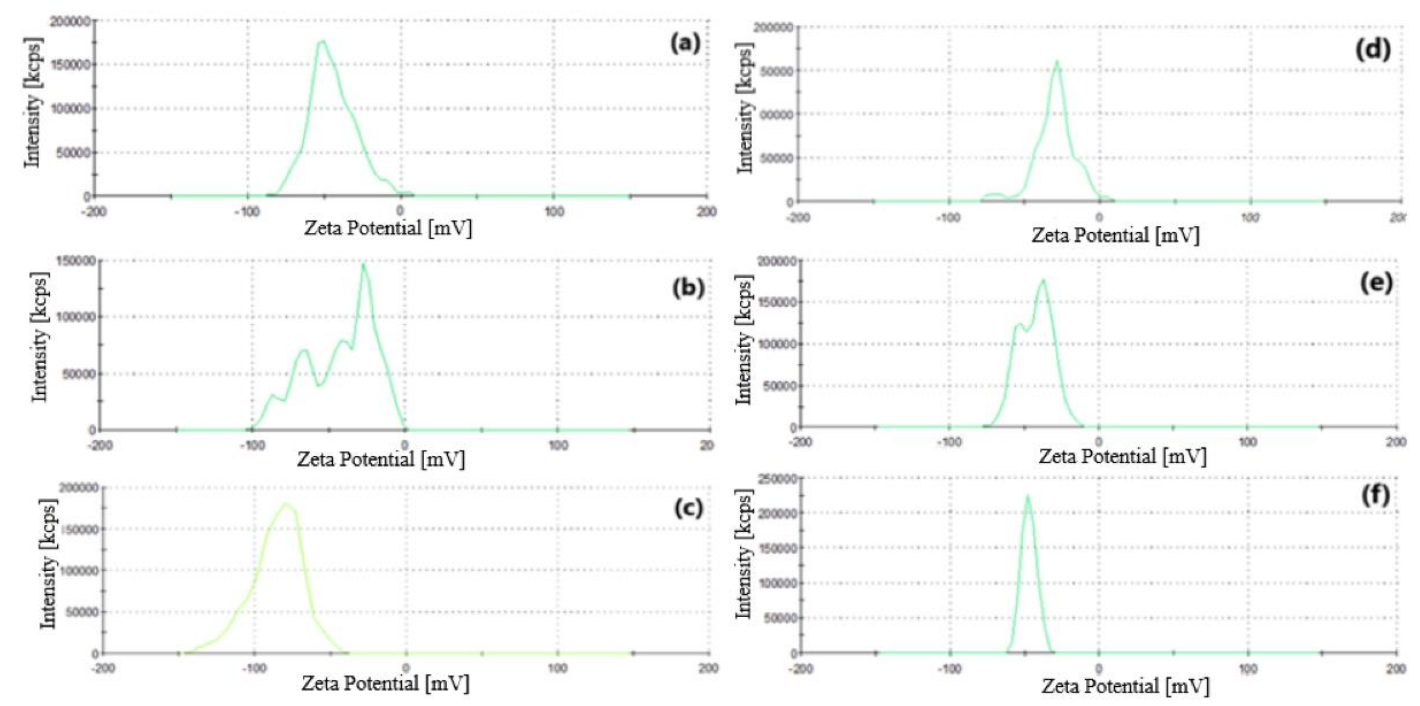

Figure 9. Zeta potential distribution of the particles: a) the initial MNPs; b) MNPs + TMOH;

c) $(\mathrm{MNPs}+\mathrm{TMOH})+$ concentrated $\mathrm{HA}$; $)(\mathrm{MNPs}+\mathrm{TMOH})+$ Inulin;

e) $((\mathrm{MNPs}+\mathrm{TMOH})+$ Inulin $)+\mathrm{HA} ; \mathrm{f})((\mathrm{MNPs}+\mathrm{TMOH})+$ Inulin $)+$ concentrated HA

\section{Conclusions}

Deployment of targeted therapy at controllable concentrations and local bioavailability had been an unmet clinical need until drug delivery systems were researched and implemented. Although widely used they are perfectible and difficult to engineer and improve due to the requirement of interdisciplinary cooperation and high level of research. We propose a system for intra-articular delivery of hyaluronic acid viscoelastic solution combined with an improved pharmaceutical formulation by double coated functionalized nanoparticles of magnetite having homogenous size. This appears to be a promising deployment method that can concentrate the nanoparticles intra-articular and prevents rapid lymphatic clearance. The synthesis of nanoparticles of magnetite was successfully achieved by a co-precipitation method, initially obtaining asymmetric nanoparticles with various dimensions, dispersed homogeneously in a viscoelastic solution matrix.

Functionalization of nanoparticles of magnetite by coating with tetramethylammonium hydroxide $(\mathrm{TMOH})$, hyaluronic acid (HA) and inulin had the effect of reducing their size and homogenizing the distribution of nanoparticles in the viscoelastic solution. After coating with TMOH, the size of the nanoparticles was reduced to $46 \mathrm{~nm}$ from $100 \mathrm{~nm}$ (the size of the MNPs initially synthesized), preventing the formation of magnetic nanoparticle agglomerations.

From the DLS analysis it was found that the addition of an inulin layer did not have a significant 
influence on the size of the nanoparticles compared to the HA and TMOH coating, but a higher concentration of hyaluronic acid caused an exaggerated increase in nanoparticle size.

Delivery of functionalized nanoparticles of magnetite with the help of a magnet ensures localization of the particles in the desired area, and optimization of the coatings by the aforementioned method prevents the delivery of large sized particles. These contribute to a longer residual time of the active substance in the joint by impeding lymphatic clearance, and reduce crystallization and toxicity complications.

\section{References}

1.JORGE L.E.I., MAUMITA B., EMMANUEL K., LAKSHMI S.N., CATO T.L., Regenerative Engineering for Knee Osteoarthritis Treatment: Biomaterials and Cell-Based Technologies, Engineering, 3(1), 2017, p. 16-27.

2.NICOLETA B, OLIVIER J., ERIC D., Intra-articular drug delivery systems for the treatment of rheumatic diseases: A review of the factors influencing their performance, Eur. J. Pharm. Biopharm., 73(2), 2009, p. 205-218.

3.PIERRE M., OLIVIER J., ERIC A., Recent advances in intra-articular drug delivery systems for osteoarthritis therapy, Drug Discovery Today, 23(10), 2018, p.1761-1775.

4.RODICA M., DAN L., IULIAN A., CRISTIAN P., Development of Modified Viscoelastic Solution with Magnetic Nanoparticles - Potential Method for Targeted Treatment of Chondral Injuries, Biommedd V, 583, 2014, p. 145-149.

5.SIMONA C., IULIAN A., LUMINITA F., ILEANA M., CLAUDIA M., LASLO V., SIMONA V., AUREL M., Surface modifications of the titanium mesh for cranioplasty using selenium nanoparticles coating, J Adhes Sci Technol, 32(22), 2018, p. 2509-2522.

6.ANA-IULIA B., AURORA A., COSMIN C., EUGENIU V., ION C., MARIUS N., IULIAN A., In vitro degradation and corrosion evaluation of $\mathrm{Mg}-\mathrm{Ca}$ alloys for biomedical applications, $J$. Optoelectron. Adv. M., 18(3-4), 2016, p. 394-398.

7.ANTONIAC I; NEGRUSOIU M; MARDARE M; SOCOLIUC C; ZAZGYVA A; NICULESCU M; Adverse local tissue reaction after 2 revision hip replacements for ceramic liner fracture A case report, Medicine, 96(19), 2017, p. 1-5.

8.ANA-IULIA B., STAN GE; MARIUS N., ION C., EUGENIU V., IULIAN A., Adhesion evaluation of different bioceramic coatings on $\mathrm{Mg}$-Ca alloys for biomedical applications, $J$ Adhes Sci Technol, 30(18), 2016, p. 1968-1983.

9.GEORGE P., CARMEN M., IULIAN A., Dependency between the porosity and polymeric structure of biomaterials used in hernia surgery and chronic mesh-infection, Mater. Plast., 52(4), 2015, 484-486.

10.IULIAN A., MARIAN B., RAZVAN I., FLORIAN B., IOL's opacification: a complex analysis based on the clinical aspects, biomaterials used and surface characterization of explanted IOL's, Mater. Plast., 52(1), 2015, 109-112.

11.MONICA C., CATALIN C., IULIAN A., OCTAVIAN M., Levonorgestrel-releasing intrauterine systems: Device design, biomaterials, mechanism of action and surgical technique, Mater. Plast., 52(2), 2015, p. 258-262.

12.COSMIN S., LIVIU M., MEDA N., LAURA R., LAVINIA A., MIHAI R., IULIAN A., FLORIN T., ADRIAN P., New metallic nanoparticles modified adhesive used for time domain optical coherence tomography evaluation of class II direct composite restoration, Rev. Chim., 63(4), 2012, 380-383.

13.CODRUTA S., ALEXANDRU B., AURORA A., STANCA B., CAMELIA A., IULIAN A., MARIOARA M., The nanofiller effect on properties of experimental graphene dental nanocomposites, J Adhes Sci Technol, 3(16), 2016, p. 1779-1794.

14.SIMONA C., EARAR K., VASILE L., LUMINITA F., TRAIAN C., IULIAN VASILE A., Ecofriendly, Facile and Rapid Way for Synthesis of Selenium Nanoparticles Production, structural and morphological characterization, Rev. Chim., 68, (12), 2017, 2963-2966. 
15.PRISCILA da COSTA C.J., DIOGO S.P., ANTONIO CLAUDIO T., Materials for Biomedical Engineering: Nanomaterials-based Drug Delivery, Chapter 12, Magnetic nanoparticles: applications in biomedical processes as synergic drug-delivery systems, Elsevier Inc., 2019, p. 371-396.

16.RICCARDO G., CHIARA G., GLORIA B., LUCA S., LETIZIA F., FRANCESCO SAVERIO L., ADRIANO P., IULIAN A., ERIBERTO B., Graphene-Based Nanomaterials for Tissue Engineering in the Dental Field, Nanomaterials, 8(5), 2018, p. 1-31.

17.FLORINA D.C., VERA B., MARCEL I.P., ANDREI L., AURORA A., IULIAN V.A., LILIANA V., Biopolymers - Calcium Phosphates Composites with Inclusions of Magnetic Nanoparticles for Bone Tissue Engineering, Int. J. Biol. Macromol., 125, 2019, p. 612-620.

18.MARGARETHE H.A., HEINRICH H., XAVIER M., Superparamagnetic nanoparticles - a tool for early Diagnostics, Swiss Med. Wkly, 140, 2010, p. 7-13.

19.TUDOR P., BOGDAN ALEXANDRU S., OANA P., ANCUTA G., CARMEN C., IULIAN A., LUCIAN B.T., Preparation and cytocompatibility evaluation for hydrosoluble phosphorous acidderivatized cellulose as tissue engineering scaffold material, J. Mater. Sci.: Mater. Med., 25(4), 2014, p. 1115-1127.

20.JULIETA VR., IULIAN A., GIUSEPPE C., VLADIMIR SK., ANTONIO R., Bioactive Materials for Bone Tissue Engineering, Biomed Res Int, 2016, p. 1-3.

21.WILLI P., CHANDRA P.S., Biointegration of Medical Implant Materials, Chapter 13, Inorganic nanoparticles for targeted drug delivery, Elsevier Ldt., 2020, p. 333-373.

22.AJAY KUMAR G., MONA G., Cytotoxicity suppression and cellular uptake enhancement of surface modified magnetic nanoparticles, Biomaterials, 26(13), 2005, p. 1565-1573.

23.MICHAEL B., BENJAMIN S., Viscosupplementation Treatment of Arthritis Pain,CurR. PainHeadache Rep., 13(6), 2009, p. 440-446.

24.VIPUL D.P, PANKAJ M.M., Functional Polysaccharides for Biomedical Applications, Chapter 7, Hyaluronic acid as potential carrier in biomedical and drug delivery applications, Elsevier Ldt., 2019, p. 440-446.

25.IULIAN A., DAN L., CAMELIA T., CLAUDIA M., SEBASTIAN G., Osteochondral Tissue Engineering, Chapter 12, Synthetic Materials for Osteochondral Tissue Engineering, Springer International Publishing AG, 2018, p. 31-52.

26.S. VASVANI, P. KULKARNI, D. RAWTANI, Hyaluronic acid: A review on its biology, aspects of drug delivery, route of administrations and a special emphasis on its approved marketed products and recent clinical studies, International Journal of Biological Macromolecules, Available online, 9 November 2019, DOI: 10.1016/j.ijbiomac.2019.11.066.

27.ZHAI P., PENG X., LI B., LIU Y., SUN H., LI X., The application of hyaluronic acid in bone regeneration, International Journal of Biological Macromolecules, Available online, 18 November 2019, DOI: 10.1016/j.ijbiomac.2019.10.169.

Manuscript received: 9.03 .2020 